\title{
SIMULTANEOUS DETERMINATION OF ROSIGLITAZONE AND GLICLAZIDE IN PHARMACEUTICAL DOSAGE FORMS BY HIGH PERFORMANCE LIQUID CHROMATOGRAPHY
}

\author{
K.S. LAKSHMI, T. RAJESH* \\ Department of Pharmaceutical Analysis, SRM College of Pharmacy, SRM University, Kattankulathur-603203, Tamil Nadu, India.
}

(Received: September 29, 2009 - Accepted: April 8, 2010)

\begin{abstract}
A simple reverse phase high performance liquid chromatographic method was developed for the simultaneous determination of rosiglitazone (RGL) and gliclazide (GLC) in pure and pharmaceutical dosage forms. A phenomenex Gemini reverse phase $\mathrm{C}_{18}$ column $(150 \times 4.6 \mathrm{~mm}$ i.d., $5 \mu)$ was used with a mobile phase containing a mixture of acetonitrile and water $(\mathrm{pH} 3$ adjusted with ortho phosphoric acid) in the ratio of $70: 30$. The flow rate was $0.6 \mathrm{~mL} / \mathrm{min}$. and effluents were monitored at $250 \mathrm{~nm}$ and eluted at $2.41 \mathrm{~min}$. (RGL) and $5.22 \mathrm{~min}$. (GLC). Calibration curve was plotted with a range from $0.025-2.5 \mu \mathrm{g} / \mathrm{mL}$ for RGL and 0.08 to $8 \mu \mathrm{g} / \mathrm{mL}$ for GLC. The assay was validated for the parameters like accuracy $(>97.87 \%$ recovery), precision (intra-day and inter-day with $\%$ RSD $<2$ ), robustness and system suitability parameters. Hence the method was found to suitable for the routine quality control of the drugs in pure and pharmaceutical dosage forms.
\end{abstract}

KeyWords: Rosiglitazone, Gliclazide, RP-HPLC, validation, Pharmaceutical dosage forms

\section{INTRODUCTION}

Rosiglitazone [( $)$-5-[4-[2-[N-methyl- $N(2-$ pyridyl)amino]ethoxy]benzyl]2,4-dione thiozolidine] and gliclazide 1-(hexahydrocyclopenta[c]pyrrol-2(1H)yl)-3-tosylurea (Fig. 1a \& 1b) a combination of drugs belong to thiazolidine dione and sulfonyl urea groups of anti-diabetic drugs which is one of the most successful combination used in the treatment of type 2 diabetes. Rosiglitazone is highly bound to plasma proteins $(99.8 \%)$ and is primarily eliminated via metabolism in the liver by "cytochrome P450 isoenzyme $2 \mathrm{C} 8$ exert the glucose-lowering effect by binding to peroxisome proliferator-activated receptors gamma (PPAR $\gamma$ )" thus increasing the receptor sensitivity to insulin ${ }^{1-3}$ where as gliclazide act by increasing the secretion of insulin by the functioning $\beta$-cells of the pancreas ${ }^{4}$.
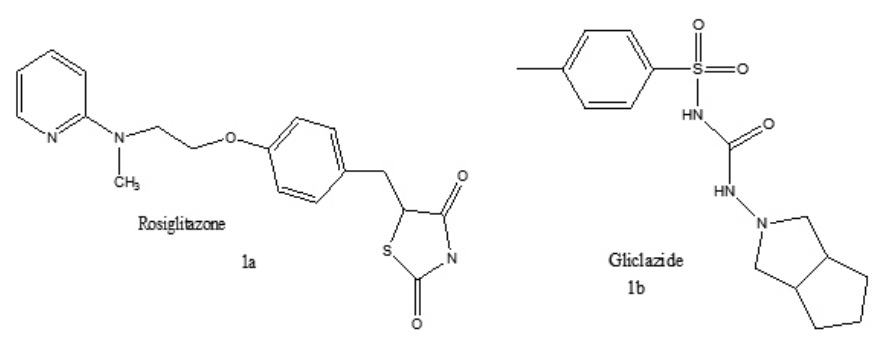

Fig. 1: structure of (a) rosiglitazone and (b) gliclazide.

The literature reveals few reported methods for rosiglitazone and gliclazide individually on HPLC, HPTLC and LC-MS ${ }^{5-8}$ and a method on $\mathrm{HPTLC}^{9}$ in combination dosage forms. As the combination of rosiglitazone and gliclazide is one of the successful combination therapies of diabetes mellitus type II (thiazolidienedione and sulfonyl ureas). Commercially this combination is available as tablet dosage forms with gliclazide $80 \mathrm{mg}$ and rosiglitazone 1 and $2 \mathrm{mg}$ dose. Hence it is necessary to develop a method to determine the combination in pure and formulations. The present paper describes a simple, sensitive, validated and economic method for the simultaneous determination of rosiglitazone and gliclazide.

\section{EXPERIMENTAL}

\section{MATERIALS AND REAGENTS:}

Rosiglitazone $(99.5 \%)$ and Gliclazide $(99 \%)$ were obtained from Orchid Chemicals and Pharmaceuticals Ltd, Chennai, India. Acetonitrile and Methanol (HPLC grade, Rankem, New Delhi, India), water (Milli Q). Other reagents were of AR grade. The formulations were purchase from the local pharmacy.

\section{CHROMATOGRAPHIC CONDITIONS:}

The HPLC system consisted of Shimadzu Class LC-10AT vp and LC20AD pumps connected with SPD-10A vp UV-Visible detector. The data acquisition was performed by Spincotech software version 1.7. Analysis was carried out at $250 \mathrm{~nm}$ using a phenomenex Gemini $\mathrm{C}_{1}$ reverse phase column $(150 \times 4.6 \mathrm{~mm}$ i.d., $5 \mu \mathrm{m})$ at room temperature i.e., $25 \pm 2{ }^{\circ} \mathrm{C}$. The mobile phase consisted of Acetonitrile: water ( $\mathrm{pH} 3$ adjusted with ortho phosphoric acid) in the ratio of $(70: 30, \mathrm{v} / \mathrm{v})$ and that was set at a flow rate of $0.6 \mathrm{~mL} / \mathrm{min}$.

PREPARATION OF STOCK AND SAMPLE SOLUTIONS:

The standard stock solutions were prepared with methanol to give the final concentration of $1000 \mu \mathrm{g} / \mathrm{mL}$. The working standard solutions of RGL and GLC were prepared by taking suitable aliquots of drug solution from the standard solutions and the volume was made up to $10 \mathrm{~mL}$ with mobile phase to get concentrations of $0.025-2.5 \mu \mathrm{g} / \mathrm{mL}$ for RGL and 0.08 to $8 \mu \mathrm{g} / \mathrm{mL}$ for GLC.

For the analysis of pharmaceutical dosage forms, ten tablets were weighed and powdered. A quantity equivalent to one tablet containing 2 $\mathrm{mg}$ of rosiglitazone and $80 \mathrm{mg}$ of gliclazide was transferred into extraction flask, to this suitable amount of methanol was added and the mixture was subjected to vigorous shaking for $30 \mathrm{~min}$. to completely extract drugs, and then centrifuged at $5000 \mathrm{rpm}$ for $20 \mathrm{~min}$ (Remi R8C laboratory centrifuge). Supernatant was collected from each set and diluted with mobile phase to get a final concentration with in linearity range and injected to HPLC system for the analysis.

\section{RESULTS AND DISCUSSION}

The chromatographic conditions were optimized by changing the composition of mobile phase where different ratios were experimented to optimize the mobile phase. Finally a mixtute of Acetonitrile and water $(\mathrm{pH}$ 3 adjusted with ortho phosphoric acid) in the ratio of 70: 30 was used which eluted better resolved peaks $\left(R_{\mathrm{s}}-3.93\right)$ of both the drugs which are symmetric with minimum tailing (1.37 and 1.4 for RGL and GLC respectively).

A typical chromatogram obtained by using the aforementioned mobile phase from $20 \mu \mathrm{L}$ of the assay preparation is illustrated in Fig. 2. The retention factors of RGL and GLC were 2.41 and 5.22 min., respectively. 


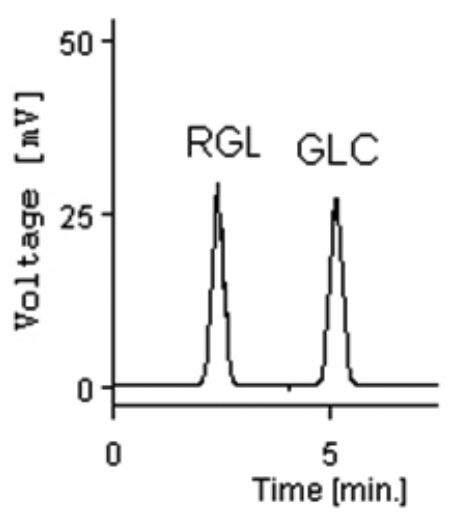

Fig. 2: A typical chromatogram showing the peaks of rosiglitazone and gliclazide in bulk.

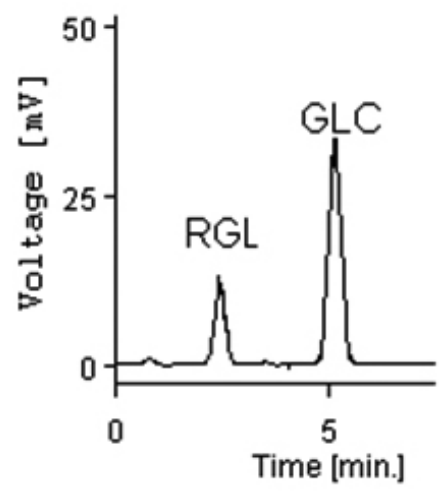

Fig. 3: A typical chromatogram showing the peaks of rosiglitazone and gliclazide in pharmaceutical dosage forms.

The linearity of the method was tested from $0.025-2.5 \mu \mathrm{g} / \mathrm{mL}$ for RGL $(0.025,0.05,0.1,0.5,1.0,1.5$ and $2.5 \mu \mathrm{g} / \mathrm{mL})$ and 0.08 to $8 \mu \mathrm{g} / \mathrm{mL}$ for GLC $(0.08,0.16,0.32,1.6,3.2,6.4$ and $8 \mu \mathrm{g} / \mathrm{mL})$. Solutions were injected in triplicate and the calibration graphs were plotted as peak area of the analyte against the concentration of the drug in $\mu \mathrm{g} / \mathrm{ml}$. In the simultaneous determination, the calibration graphs were found to be linear for both the analytes in the mentioned concentrations and the correlation coefficients for the regression line were 0.9986 and 0.9991 for RGL and GLC respectively. The accuracy of the method was studied by recovery experiments. The recovery experiments were performed by adding known amounts of the drug to the placebo. The recovery was determined at three levels, viz. $50 \%, 100 \%$, and $150 \%$ of the selected concentrations. Three samples were prepared for each recovery level. The recovery values for GLC and RGL ranged from $98.26-101.93 \%$ and $97.76-$ $100.34 \%$, respectively (Table 1 ). The precision (repeatability and intermediate precision) of the method was determined from one lot of combined dosage form. Intra and Inter day studies were performed by taking six replicates of three concentrations. The results are shown in (Table 2). The limit of detection (LOD) and limit of quantification (LOQ) for RGL, GLC was $0.006 \mu \mathrm{g} / \mathrm{ml}$, $0.008 \mu \mathrm{g} / \mathrm{ml}$ and $0.02 \mu \mathrm{g} / \mathrm{ml}, 0.025 \mu \mathrm{g} / \mathrm{ml}$, respectively was calculated by using signal-to-noise ratio ( $\mathrm{S} / \mathrm{n}=3$ for $\mathrm{LOD}$ and $\mathrm{S} / \mathrm{n}=10$ for $\mathrm{LOQ}$ ) and by dilute sample solutions. To determine the robustness of the developed method experimental conditions were purposely altered like mobile phase composition (68 to $72 \%$ ), mobile phase $\mathrm{pH}$ (2.9 to 3.1$)$ and flow rate $(0.5$ to $0.7 \mathrm{~mL} / \mathrm{min}$.) and $\mathrm{RSD}$ of the peak areas of RGL and GLC were found less than 2.0 illustrate the robustness of the method.
Table 1: Recovery of RGL and GLC ( $\mathrm{n}=3)$.

\begin{tabular}{|c|c|c|c|c|c|c|c|c|}
\hline \multirow[t]{3}{*}{ Sample ID } & \multicolumn{4}{|c|}{ Concentration of drug $(\mu \mathrm{g} / \mathrm{ml})$} & \multicolumn{2}{|c|}{$\%$ Recovery } & \multicolumn{2}{|l|}{$\%$ RSD } \\
\hline & \multicolumn{2}{|c|}{ Pure Drug } & \multicolumn{2}{|c|}{ Formulation } & \multirow[b]{2}{*}{ GLC } & \multirow[b]{2}{*}{ RGL } & \multirow[b]{2}{*}{ GLC } & \multirow[b]{2}{*}{ RGL } \\
\hline & GLC & RGL & GLC & RGL & & & & \\
\hline $50 \%$ & 40 & 1.0 & 80 & 2 & 99.22 & 97.87 & 1.76 & 2.12 \\
\hline $100 \%$ & 80 & 2.0 & 80 & 2 & 98.23 & 100.11 & 1.89 & 1.32 \\
\hline $150 \%$ & 120 & 3.0 & 80 & 2 & 99.49 & 98.73 & 2.34 & 1.90 \\
\hline
\end{tabular}

Tabel 2: Precision data for RGL and GLC.

\begin{tabular}{|c|c|c|c|c|}
\hline & \multicolumn{2}{|c|}{ Nominal concentrations $(\mu \mathrm{g} / \mathrm{ml})$} & \multicolumn{2}{|c|}{ Mean \pm S.D } \\
\hline & GLC & RGL & GLC & RGL \\
\hline 1 & 40 & 1.0 & $39.67 \pm 0.52$ & $0.96 \pm 0.01$ \\
\hline 2 & 60 & 1.5 & $58.76 \pm 0.95$ & $1.49 \pm 0.01$ \\
\hline 3 & 80 & 2.0 & $78.35 \pm 1.69$ & $1.86 \pm 0.03$ \\
\hline
\end{tabular}

Each mean value is the result of triplicate analysis for three times a day

Table 3: Results of the determination of rosiglitazone and gliclazide in Tablets $(\mathrm{n}=6)$.

\begin{tabular}{lcccc}
\hline & $\begin{array}{c}\text { labeled } \\
\text { amount }(\mathbf{m g})\end{array}$ & $\begin{array}{c}\text { Amount }(\boldsymbol{\mu g}) \\
\text { Found } \pm \text { S.D }\end{array}$ & $\begin{array}{c}\text { Assay } \\
\text { \%oRSD }\end{array}$ & \%w/w \\
\hline GLYROZ-2 & & & & \\
GLC & 80 & $78.76 \pm 1.75$ & 2.22 & 98.45 \\
RGL & 2 & $2.03 \pm 0.04$ & 1.97 & 101.50 \\
ROSINORM-G & & & & \\
GLC & 80 & $79.32 \pm 1.46$ & 1.84 & 99.15 \\
RGL & 2 & $1.97 \pm 0.03$ & 1.52 & 98.50 \\
\hline
\end{tabular}

APPLICATION OF THE METHOD TO PHARMACEUTICAL DOSAGE FORMS:

The method is sensitive and specific for the quantitative determination of RGL and GLC and also subjected to validation for different parameters, hence applied for the estimation of drug in pharmaceutical dosage forms. Tablets from two different manufacturers were evaluated for the amount of RGL and GLC present in the formulations. Each sample was analyzed in triplicate after extracting the drug as mentioned above in experimental section. The amount of RGL and GLC was found to be within the range of $98 \%-102 \%$. None of the tablet excipients were found to interfere with the analyte peak (Fig 3) and the results are shown in Table 3.

\section{CONCLUSION}

The proposed method was found to be simple, precise, accurate and rapid for simultaneous determination of rosiglitazone and gliclazide from pure and in pharmaceutical dosage forms. The mobile phase is simple to prepare and economical. The sample recoveries in all formulations were in good agreement with their respective label claims and they suggested non-interference of formulation excipients in the estimation. Hence, the method can be easily and conveniently adopted for routine analysis of rosiglitazone and gliclazide in combined dosage forms and can also be used for dissolution or similar studies. 


\section{REFERENCES}

1. J.M. Lehmann, L.B. Moore, T.A. Smith-Oliver, W.O. Wilkison, T.M. Wilson, S.A. Kliewer, J. Bio. Chem., 270, 12953 (1995)

2. T.M. Wilson, J.E. Cobb, D.J. Cowan, R.W. Wiethe, I.D. Correa, S.R Prakash, K.D. Beck, L.B. Moore, S.A. Kliewer, J.M. Lehmann, J. Med. Chem., 39, 665 (1996)

3. P.W. Young, D.R. Buckle, B.C. Cantello, H. Chapman, J.C. Clapham, P.J. Coyle, D. Haigh, R.M. Hindley, J.C. Holder, H. Kallender, A.J. Latter, K.W. Lawrie, D. Mossakowska, G.J. Murphy, L. Roxbee Cox, S.A. Smith, J. Pharmacol. Exp. Ther., 284, 751 (1998)
4. R.S. Satoskar, S.D. Bhandarkar, N. Nirmala, Pharmacology and Pharmacotherapeutics, Rev $19^{\text {th }}$ Ed. 893

5. Gulshan Bansal, Manjeet Singh, Kaur Chand Jindal, Chromatographia, 66, 751 (2007)

6. Guixia Ling, Jin Sun, Jingling Tang, Xiaodi Xu, Yinghua Sun, Zhonggui He, Anal. Lett., 39, 1381 (2006)

7. Chi-Chi Chou, Maw-Rong Lee, Fu-Chou Cheng, Dar-Yu Yang, $J$. Chromatogr. A, 1097, 74 (2005)

8. J. He, Y. Hu, L.F. Duan, Z.R. Tan, L.S. Wang, J. Pharm. Biomed. Anal., 43, 580 (2007)

9. S. Gayatri, A. Shantha, V. Vaidyalingam, Ind. J. Pharm. Sci., 65, 663 (2003). 